\title{
An academic, pharmaceutical and practice collaboration to implement asthma guidelines
}

\author{
Colin McCowan*, Ron G. Neville, Gaylor Hoskins
}

Mackenzie Building, University of Dundee, Tayside Centre for General Practice, Kirsty Semple Way, Dundee, DD2 4BF, UK

Received 9 September 2004; accepted 31 October 2004

\section{KEYWORDS \\ Asthma; \\ Primary care; \\ Guidelines; \\ Nurse review}

\section{Introduction}

Guidelines have been available for the management of asthma in the UK since the late 1980's. There

* Corresponding author. Tel.: +441382 420000;

fax: +441382 420010 .

E-mail address: c.mccowan@dundee.ac.uk (C. McCowan).

\begin{abstract}
Summary
Aims: To investigate whether a patient review service cianges the management of asthma in accordance with BTS/SIGN Guidelines.

Methods: An observational study of idut ne Grie $_{N}$ consultations for patients with asthma registereinat 062 practices throughout the United Kingdom. Practices recorded $i \in v \in$ 's on a computer templ hit a a ceturned the information to an acadeniic. unit for analysis.

Results: 41,493 patient; r raa data returned with 14,790 (36\%) patients reporting s/njorn. diest or on a daily basis and 15,840 (38\%) patients overusing their shortacting $\beta 2$-agonist. 4,556 (74\%) of patients with symptoms who had a subsequent consultation reported a reduction in their symptoms, whilst 3,932 (63\%) reported a reduction in short-acting $\beta 2$-agonist use. Night-time, daytime, and activity symptom scores, and short-acting $\beta 2$-agonist use, were significantly reduced for patients reviewed more than once.

Conclusion: There are a large proportion of patients suffering symptoms at rest or on a daily basis. There was a significant reduction in symptom levels and use of reliever medication for patients who were reviewed. A review service implementing the BTS/SIGN guidelines for asthma management would seem to improve patient outcomes.

( 2005 General Practice Airways Group. Published by Elsevier Ltd. All rights reserved.
\end{abstract}

have been several revisions with the most recent being in the public domain since late 2001 with publication in early 2003 [1]. There have been a variety of research and audit initiatives over the last 20 years, which aimed to improve the process of asthma care within general practices. Many of these have shown positive results with some projects reporting improvements in patient outcomes as well 
as in the process of care [2-5]. There remains a problem with implementation of guidelines into routine clinical care [6].

A recent survey to investigate whether Scottish practices adhered to the guidelines found that almost all practices offered a review service and had trained asthma nurses providing care for patients [7]. However, relatively few practices were running routine searches to identify patients who were deemed to be at risk or who had high levels of symptoms. Those that did identify patients in these ways, reported asking the patients for review.

Although pharmaceutical companies have played a role in distributing asthma guidelines and providing funding for specialist training for nurses, industry collaboration in the process of implementation remains controversial. The new SIGN/BTS Asthma Guideline published in early 2003 re-emphasised the need for review services and appropriate training for people managing patients with asthma [1]. The identification and targeting of patients who may benefit from a review, and regular participation in clinical audit, were two key recommendations. Another recommendation was the use of a tool to provide a structured consultation. Whilst some previous studies have supported these reommendations, the evidence base was not jeerned strong.

An educationat asthrial service for practicts I vas developed in vider to identify ard ren arge patients who could benefit from a review with an asthma nurse. The project was designed to meet the following recommendations:

- In primary care, patients with asthma should be reviewed regularly by a nurse with training in asthma management.

- General practices should maintain a list of patients with asthma.

- Clinical review should be structured and should utilise a standard recording system.

- Feedback of information to clinicians should link individual patients with recommendations from guidelines.

- Offer a customised 'asthma action plan' to all people with asthma.

- Practices should offer nurse-run structured care for targeted patients with asthma.

- Health professionals should be involved in clinical audit.

- Identify groups of patients at risk: Patients using large quantities of $\beta 2$-agonists.

- Monitor the proportion of patients with active disease or taking asthma treatment: who are able to use their prescribed inhalers effectively; with normal lung function; with an 'asthma action plan'.

- Recommended tools for monitoring morbidity: RCP three questions, or tools which incorporate these.

Previous attempts to change the care of patients with asthma in line with guidelines have been unidimensional interventions looking at practice nurse training, audit, or therapeutic initiatives [8-12]. In reality, practices draw on a wide repertoire of supports to effect changes in clinical practice and can be adept at using support from industry, health authorities, and academic units. The provision of an asthma service to support the clinical skills of GPs and nurses was developed, combining a network of skilled respiratory care nurses (employees of a pharmaceutical company) blended with the analytic skills of an academic unit. This paper describes an attempt to implement asthma guidelines using a multi-faceted academic, pharmaceutical, and clinical approach.

\section{Method}

evien service

Asernce to support UK practices in managing patients according to asthma guidelines was developed using the analytic skills of the Asthma Research Unit (ARU) at the University of Dundee, the Allen \& Hanburys (part of GlaxoSmithKline) network of Respiratory Care Associates (RCAs) and the clinical skills of practice staff. The RCAs would be responsible for recruitment of practices and supporting the work of the nurse within the clinic. RCAs are separate from promotional representatives and are precluded by the Advisory Body on the Pharmaceutical Industry (ABPI) guidelines from encouraging the use of specific proprietary products. The ARU was responsible for developing the reports and analysing the data. Data on individual practices or patients was not made available to the pharmaceutical company, except for the purposes of report feedback by the RCAs, to which the practices had given prior agreement.

\section{Patients}

Practices throughout the UK were offered an electronic asthma patient review service. RCAs helped practices set up disease registers, check prescribing records to identify patients using excessive amounts of $\beta 2$-agonist medication, and in- 
vite those patients for a structured clinical review according to guideline recommendations. The review addressed inhaler technique, use of selfmanagement plans, compliance, education, and therapeutic change if necessary. If patients gave written consent, their details (in anonymous form) were compiled into a practice audit and sent to the research unit for analysis. The analysis compared each patient's management with guidelines. Practices then received a comprehensive report on a quarterly basis showing where patients' management concurred with guidelines, where it diverged, and what changes could be effected if necessary. The RCAs were not involved in the compilation of the audit reports but were available to help practices discuss and interpret them. Practices also reported information on practice size and the organisation of their asthma care.

\section{Follow up and analysis}

Practices were encouraged to return the anonymised data on supplied, labelled floppy disks to the research unit using postage-paid pre-addressed envelopes. The information from the returned disks was imported to a database for further analysis. Once a practice had returned data spanrirg a hree month period, a clinical alidic report was generated highlightin basethel Earacteristics of rellewed patients and any cnanges in so. and symptoms recorded over time. This report was then fed back to the practice by the local RCA. This report was repeated for data returned from a practice for periods of six, nine and 12 months as well. Practice characteristics and the organisation of their asthma care were analysed from the data recorded in the database collated from all the practice returns.

The first consultation record for each patient in the study was then analysed. The level of symptoms, reported short-acting $\beta 2$-agonist use, measures of compliance and inhaler technique, and prescribed medication were all examined. The records of patients who reported night-time or daytime symptoms on a daily basis, or who reported symptoms on activity, were marked. The database was then examined for any subsequent consultations by these patients and any change in level of symptoms recorded. Interventions made during the initial and subsequent consultations were also recorded.

Patients who reported overusing their shortacting $\beta 2$-agonist were also followed up to see if any reduction in their symptoms at further consultations also reduced the level of $\beta 2$-agonist use. Overuse of a short-acting $\beta 2$-agonist was defined as "more than once a day for patients at BTS/SIGN
Management step 3 and below, or more than twice a day for those patients at steps 4 and 5."

The data was stored using a Microsoft Access database and further analysis was carried out using SPSS for Windows version 10.1. The results are presented as simple percentages or means and where appropriate odds ratios have been used. The return and analysis of data by members of the research unit was given ethical approval from the Tayside Medical Ethics Committee. Data were held with regard to the Data Protection Act 1998.

\section{Results}

A total of 862 practices returned data on 41,493 patients. The average practice population reported was 6,637, with an average of two nurses and four general practitioners working at each practice. The average number of patients reported on the asthma register was 449 , giving a prevalence figure of slightly under $6.8 \%$.

Overall the number of patients recorded in the database related to $11 \%$ of thio es 5 -innated asthma register for the praftices, al hough this ranged from urider $1 \%$ trough to the entire register for individual practices Other aspects of the reported organisation of las thina care in the practices can be seen in Table 1 , with $73 \%$ of practices employing

Table 1 Organisation of practice care.

\begin{tabular}{|c|c|c|}
\hline Practice size & & $\begin{array}{l}\text { Standard } \\
\text { error }\end{array}$ \\
\hline Mean no. of WTE GPs & 3.92 & 0.10 \\
\hline Mean no. of WTE nurses & 2.39 & 0.05 \\
\hline $\begin{array}{l}\text { Mean reported practice } \\
\text { population }\end{array}$ & 6,637 & 127 \\
\hline Mean reported asthma list & 449 & 13 \\
\hline Asthma clinic organisation & & Percentage \\
\hline Not recorded & 86 & $10 \%$ \\
\hline In general surgery & 224 & $26 \%$ \\
\hline Nurse-led clinic & 499 & $58 \%$ \\
\hline $\begin{array}{l}\text { CDM approved at a fixed } \\
\text { time }\end{array}$ & 22 & $3 \%$ \\
\hline $\begin{array}{l}\text { CDM approved at variable } \\
\text { times }\end{array}$ & 32 & $4 \%$ \\
\hline \multicolumn{3}{|l|}{ Process of asthma care } \\
\hline $\begin{array}{l}\text { Nurse with accredited } \\
\text { diploma }\end{array}$ & 628 & $73 \%$ \\
\hline Practice owns a nebuliser & 746 & $87 \%$ \\
\hline $\begin{array}{l}\text { Practice has previously } \\
\text { used Tayside Asthma } \\
\text { Stamp }\end{array}$ & 441 & $51 \%$ \\
\hline $\begin{array}{c}\text { Practice has completed an } \\
\text { audit in the last } 3 \text { years }\end{array}$ & 502 & $58 \%$ \\
\hline
\end{tabular}


Table 2 Age breakdown at first consultation.

\begin{tabular}{lcc}
\hline Age & No. of patients & Percentage \\
\hline Under 5 & 1,234 & 3 \\
$5-12$ & 6,322 & 15 \\
$13-44$ & 14,608 & 35 \\
$45-64$ & 11,588 & 28 \\
$65+$ & 7,685 & 19 \\
\hline
\end{tabular}

56 patients had no age recorded.

a nurse with an accredited asthma diploma. There were 18,567 male patients reported on by the practices $(45 \%)$ and the age distribution at the first consultation is as shown in Table 2.

The medication use recorded for each patient prior to the first consultation was examined and the SIGN/BTS treatment step calculated (see Table 3). $83 \%$ of the patients were receiving prophylactic medication. A total of 14,790 patients $(36 \%)$ reported night-time or daytime symptoms on a daily basis, or had symptoms at rest (see Table 4). Almost one third of all patients, $(13,320 ; 32 \%)$, reported that they were not taking their prophylactic medication as prescribed, and one in ten, $(3,945 ; 10 \%)$, reported days lost from school or work. A similar proportion was classed as having poor inhaler tech. nique, $(4,243 ; 10 \%)$.

To date we are able to repert (o) 0, 164 patients (42\%) with a furtherourisuty ation from the orbith of
Table 3 BTS/SIGN management step prior to initial consultation.

\begin{tabular}{lcc}
\hline BTS/SIGN step & No. of patients & Percentage \\
\hline No treatment & 2,373 & 6 \\
1 & 4,967 & 12 \\
2 & 18,589 & 45 \\
3 & 8,610 & 21 \\
4 & 6,741 & 16 \\
5 & 213 & 1 \\
\hline
\end{tabular}

14,790 who reported night-time or daytime symptoms on a daily basis, or who had symptoms at rest at their first consultation. Clinical interventions to asthma management were as follows: 4,184 (68\%) had a change to their medication; $4,135(67 \%)$ received education; 4,188 (68\%) were issued a new self management plan; 1,511 (25\%) had improved recorded compliance; and 934 (15\%) had their inhaler technique improved. There were 4,556 patients (74\%) who had their daily symptoms, or symptoms at rest, resolved (see Table 5). Patients whose symptoms were not resolved were mpre likely to receive education $(\mathrm{OR}=0.56,95 \%(\mathrm{I})=0.0 .0 .75)$ and were also rhorle Vike to have their inhaler techniqull:iranroved $(\mathrm{OR}=0.76(0.65-0.88))$.

There vere $158(1)$ atients $(38 \%)$ who were classifiea a Doverusing their short-acting $\beta 2$-agonists, and they were more likely to report daily symptoms

Table 4 Symptom scores \& short-acting $\beta 2$-agonist overuse.

\begin{tabular}{|c|c|c|c|}
\hline & All patients (\%) & $\begin{array}{l}\text { Overusing short } \\
\text { acting } \beta 2 \text {-agonist }\end{array}$ & $\begin{array}{l}\text { Percentage } \\
\text { overusing } \\
\end{array}$ \\
\hline No. of patients & 41,493 & 15,840 & $38 \%$ \\
\hline \multicolumn{4}{|c|}{ Night time symptom score } \\
\hline 0 & $20,823(50 \%)$ & 4,591 & $22 \%$ \\
\hline 1 & $6,827(16 \%)$ & 2,550 & $37 \%$ \\
\hline 2 & $7,113(17 \%)$ & 4,168 & $59 \%$ \\
\hline 3 & $6,730(16 \%)$ & 4,531 & $67 \%$ \\
\hline \multicolumn{4}{|l|}{ Day time symptom score } \\
\hline 0 & $11,572(28 \%)$ & 1,434 & $12 \%$ \\
\hline 1 & $8,396(20 \%)$ & 1,908 & $23 \%$ \\
\hline 2 & 9,547 (23\%) & 4,356 & $46 \%$ \\
\hline 3 & $11,978(29 \%)$ & 8,142 & $68 \%$ \\
\hline \multicolumn{4}{|l|}{ Activity symptom score } \\
\hline 0 & $13,921(34 \%)$ & 2,319 & $17 \%$ \\
\hline 1 & $13,441(32 \%)$ & 5,368 & $40 \%$ \\
\hline 2 & $10,233(25 \%)$ & 5,474 & $57 \%$ \\
\hline 3 & $3,898(9 \%)$ & 2,679 & $69 \%$ \\
\hline Days off work/school & $3,945(10 \%)$ & 2,424 & $61 \%$ \\
\hline Poor compliance & $13,320(32 \%)$ & 5,898 & $44 \%$ \\
\hline Poor inhaler technique & $4,243(10 \%)$ & 2,197 & $52 \%$ \\
\hline
\end{tabular}


Table 5 Interventions made to patients reporting daily symptoms at first consult.

\begin{tabular}{lccc}
\hline & Symptoms reduced & Symptoms daily or at rest & Odds ratio $(95 \% \mathrm{Cl})$ \\
\hline No. of patients & 4,556 & 1,608 & \\
Change in medication & $3,079(68 \%)$ & $1,105(69 \%)$ & $0.95(0.84-1.07)$ \\
Education given & $2,953(65 \%)$ & $1,182(74 \%)$ & $0.66(0.58-0.75)$ \\
Improved compliance & $1,102(24 \%)$ & $409(25 \%)$ & $0.94(0.82-1.07)$ \\
Improved inhaler technique & $646(14 \%)$ & $288(18 \%)$ & $0.76(0.65-0.88)$ \\
SMP given & $3,111(68 \%)$ & $1,077(67 \%)$ & $1.06(0.94-1.20)$ \\
\hline
\end{tabular}

at night $(\mathrm{OR}(95 \% \mathrm{Cl})=4.27(4.04-4.52))$, during the day $(O R=6.02(5.74-6.30))$ or at rest $(O R=4.08$ (3.80-4.38)). Patients overusing their short-acting $\beta 2$-agonist were also more likely to report days lost from school or work $(\mathrm{OR}=2.87(2.68-3.07))$, poor compliance $(\mathrm{OR}=1.46(1.40-1.52))$ and poor inhaler technique $(\mathrm{OR}=1.86(1.75-1.99))$.

Of the patients overusing their short-acting $\beta 2$ agonists there were 6,198 (39\%) who had further consultations recorded. Of this group 3,419 $(55 \%)$ reported reduced night-time symptoms, 3,876 (63\%) reduced daytime symptoms and 3,496 (56\%) reduced symptoms at rest. There were 5,115 (83\%) patients who reported at least one reduced symptom score and these patients were less likely to continue overusing their short-acting $\beta 2$-agonist than those whose symptoms were not resolvet $30 \%$ vs. $67 \%, \mathrm{OR}=0.21(0.18-0.24)$.

\section{Discussion}

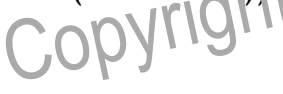

These findings suggest that implementation of the SIGN/BTS Asthma Guidelines improved patient outcomes. The finding that a sizeable proportion of patients with asthma were suffering from symptoms either daily or at rest is a cause for concern, but is in line with other recent work [13]. One of the main aims in management of patients with asthma is to alleviate symptoms to allow patients to continue unhindered in their normal life. If practices are to run an effective asthma service, it would seem imperative that regular searches to identify and treat patients with high symptom levels should be part of their routine practice, as recommended by the guidelines.

A positive aspect of the findings is that regular review appears to lead to improvement in health outcomes for patients. A nurse-led service, where a structured consultation is followed by interventions based on the guideline, can have an impressive effect. Only one in four patients continued to report their high levels of symptoms after a review consultation, and only one in three continued to overuse their short-acting $\beta 2$-agonist. Whilst we did not directly measure individual patients' quality of life, this reduction in symptoms and reliance on emergency medication is likely to have improved patients' health.

Weaknesses of the study include the reliance on self- reported data by nurses and the likelihood that 'regression to the mean' will be apparent within the results. We chose to report on follow-up data one year after the study commenced, but in the nature of real world research this meant that we had an incomplete set of follow-up consultations to analyse. The reliance on observational data means the positive effects of following the guideline may not necessarily be bov casation, but be by association. Nevever, the 'real world' setting of thle sudy in a large number of practices countrywide, shouldingal that the findings can be generally applicable to practices throughout the UK. The practices themselves performed the intervention, with logistic support from respiratory care associates and analysis support from the research unit.

The finding that patients who continued to report high levels of symptoms were more likely to receive education and also to have had their inhaler technique improved appears paradoxical, but may simply reflect the extra effort practices invest in poorly-controlled patients.

Using reduction in symptom scores, and use of a short-acting $\beta 2$-agonist, as the main outcome measures may be rather simplistic. A longer- term examination of health service resource use, or patient quality of life analysis, would provide a better method to demonstrate improved patient outcomes. However, the reduction of symptoms should be a key part of asthma management and is a key goal for many patients. A long- term continuation of this study with more longitudinal data may provide more definitive answers as to whether guideline implementation can provide lasting benefit to patients.

The study did not focus on which individual components of the guideline were responsible for improvement in patient outcomes. It may be that practice nurses are able to adapt individual pa- 
tient need to relevant sections of the guideline, so long as they have some objective 'benchmark' to work from. It would seem that the implementation of a guideline-based review service in practices throughout the UK can have a substantial impact on management, leading to improvements for individual patients.

It is a contentious issue as to whether individual practices or an academic research unit should collaborate with the pharmaceutical industry [14]. This study showed that collaboration between practices, the pharmaceutical industry and academia can help practices to provide asthma care in line with guidelines. The relationship between the three parties was based on the shared aim of improved patient care. The project did not utilise proprietary drug names in the feedback process and there was no endorsement of particular products. In conclusion, we think an academic/industry/practice collaboration represents a useful and pragmatic way forward in the quest to manage patients in line with guidelines.

\section{Conflict of Interest}

The University of Dundee is in receipt of research monies from GSK, including a project to provide an audit and analysis service for UK practices. RN is a paid advisor to the project.

\section{References}

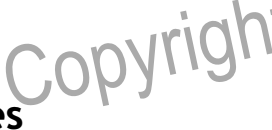

[1] British Thoracic Society, Scottish Intercollegiate Guideline Network, British Guideline on the Management of Asthma, http://www.sign.ac.uk/pdf/sign63.pdf. Accessed 2nd November 2004.
[2] Feder G, Griffiths C, Highton C, Eldridge S, Spena M, Southgate L. Do clinical guidelines introduced with practice based education improve care of asthmatic and diabetic patients? A randomised controlled trial in general practitioners in east London. BMJ 1995;311:1473-8.

[3] Bryce FP, Neville RG, Crombie IK, Clark RA, McKenzie P. Controlled Trial of an Audit Facilitator in diagnosis and treatment of childhood asthma in general practice. BMJ 1995;310:838-42.

[4] Neville RG, Hoskins G, Smith B, Clark RA. How General Practitioners Manage Acute Asthma Attacks. Thorax 1997;52:153-6.

[5] Gibson PG, Wilson AJ. The use of continuous quality improvement methods to implement practice guidelines in asthma. J Qual Clin Pract 1996;16(2):87-102.

[6] Partridge MR, Harrison BDW, Rudolph M, Bellamy D, Silverman $M$. The British Asthma guidelines - their production, dissemination and implementation. Respir Med 1998;92:1046-52.

[7] Life at the Crossroads - a Critique of the Organisation of Asthma Care in Scotland, National Asthma Campaign Scotland, 2a North Charlotte Street, Edinburgh.

[8] Neville RG, Hoskins G, Smith B, Clark RA. Observations on the Structure, Process and Outcome of Asthma Care in General Practice. Br J Gen Pract 1996;46:583-7.

[9] Liard R, Leynaert B, Zureik M, Beguin F, Neukirch F. Using global initiative on Asthma guidelines to assess asthma severity in populations. ERJ 2000;16:615-20.

[10] Bell D, Loughton AJ, Gabbay J. Isse of d c suideline based questionnaire to audit hospit.l care of aclite asthma. BMJ 1991:302:14:1(-). a )

1.] Fear. on N.G, Ryland I, Harrison BDW, on behalf of the British Thoracic Societ,'s Standards of Care Committee. National audit of acule severe asthma in adults admitted to hospital. Dㅏㄷ $1995 ; 4: 24-30$.

[12] Meng YY, Leung KM, et al. Compliance with US asthma Management guidelines and specialty care: a regional variation or national concern? J Eval Clin Pract 1999;5(2):213-21.

[13] Haughney J, Barnes G, Partridge M, Cleland J. The Living and Breathing Study: a study of patients' views of asthma and its treatment. PCRJ 2004;13(1):28-35.

[14] Smith R. Improving the care of chronic disease. BMJ 2003;327:12.

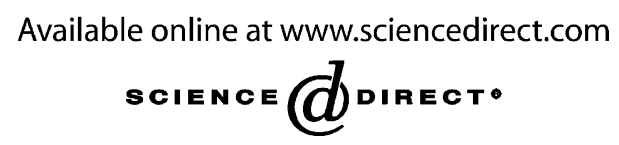

